\title{
Relations Between Anthropometric Dimensions and Overcome Resistance in Recurring Motion
}

\author{
Miroslav Dodig* \\ Independent researcher, University of Rijeka, Croatia \\ *Corresponding author: dodig@pfri.hr
}

Received May 26, 2014; Revised June 06, 2014; Accepted June 06, 2014

\begin{abstract}
The research was carried out on a sample of 124 subjects, 15-16 year old males. An analysis was performed of the relations of anthropometric body characteristics and overcome resistance in recurring motion. The evaluation of resistance in motion was based on conducting motion with $75 \%$ of the maximum achieved, overcome weight, repetitive motion is carried out until the maximum number of correctly executed repetitions. Obtained information was submitted for mathematical analysis, the MULTREG program, from the statistical program "STAT - PACK” (Gauss - Jordan, 1954, Cooley - Lohnes, 1962). On the basis of maximum cohesion and regressive coefficients, variables that measured body volume, transversal skeletal dimension and longitudinal skeletal dimension have the highest cohesion with the overcome maximum resistance in recurring motion from anthropometric body characteristics. High cohesion of variables of the overcome resistance in recurring motion with anthropometric body characteristics indicates that a part of the resistance variable in motion is expectedly significant. As the overcome maximum resistance in motion is mainly conditioned by the structure for generating intensity and duration of energy release, thus the anthropometric dimensions, especially in the volume segment, body volume and transversal skeletal dimensionality, present a factor that significantly participates in the realization of motion with increased requirements for overcoming maximum resistance in motion.
\end{abstract}

Keywords: multiple regressive analysis, relations, anthropometric dimensions, overcome maximum resistance in recurring motion

Cite This Article: Miroslav Dodig, "Relations Between Anthropometric Dimensions and Overcome Resistance in Recurring Motion.” American Journal of Educational Research, vol. 2, no. 6 (2014): 393-396. doi: 10.12691/education-2-6-11.

\section{Introduction}

The human organism has the feature of generating and releasing energy with the goal of overcoming resistance on a certain path at a certain time, within a given kinetic outlet $[4,6]$. Taking into consideration the qualitative and quantitative diversity of expression in terms of overcoming resistance within one global kinetic outlet, the possibility of forming an entire series of relations within the space of anthropometric body characteristics [1,2,5,8,9] is enabled. Preferring a certain role of anthropometric dimensions in the realization of motion where overcoming resistance is dominant, their contribution within the source of variability resistance in motion $[7,10,12,13,14]$ is a legitimate expectation. It is to be expected that the body with the larger volume and larger mass, as well as larger transversal skeletal dimensionality have a stronger impact in motions that are defined by measures of maximum resistance. The amplitude of motion is realized in recurring motion presenting the exceeded path in motion, which is defined as successive repetition of individual motion, while limited by the mechanism for generating intensity and the duration of releasing energy, what will influence the decrease of the impact of lever length. Hence, a positive impact of the volume dimension, body mass and transversal skeletal dimensionality regarding motion outcome is to be expected, where it is necessary to overcome some maximum external resistance in recurring motion.

Such a predominantly theoretical concept of the variance part of resistance will significantly be explained through parallel anthropometric dimensions determined by longitudinal, transversal, and circular dimensions of the skeleton as well as the subcutaneous adipose tissue factor. The main purpose and objective of this study is aimed towards the direction of researching mutual relationships and relations of overcome resistance in motion with anthropometric body dimensions.

\section{Methods}

The sample of subjects for this research study amounted to 124 subjects, of male gender ranging from 15 to 16 years of age. The planned sample of 124 subjects, represents the effect sufficient for any correlation coefficient equal to or larger than .23, consider different from zero with a margin of error lesser than 0.1 or a .99 degree of reliability. 
Pursuant to the goal and purpose of the research measuring instruments that have already been validated in the author's prior researches were used (M. Dodig, 2010), and were selected in a manner so as to cover all dimensions of the hypothetical model.

Variables for the evaluation of anthropometric characteristics;

- Longitudinal skeletal dimensionality; 1 . body height (ATV), 2. leg length (ADN), 3. arm length (ADR), 4. biacromial range (ASK).

- Transversal skeletal dimensionality; 1. elbow diameter (ADL), 2. wrist diameter (ADRZ), 3. knee diameter (ADK).

- Body volume and bulk; 1 . body weight (AT), 2. midrange of chest (AOG), 3. upper arm magnitude - extended $(\mathrm{AON}), 4$. upper arm magnitude - bent (AONK), 5. shin magnitude (AOP).

- Subcutaneous tissue; 1. cutaneous back fold (AKNL), 2. cutaneous stomach fold (AKNT), 3. cutaneous shin fold (AKNP).

Variables for evaluation of overcome resistance in recurring motion;

1. lifting with legs from squat (ESDNKG), 2. Pushing with hands from lying position (ESDRKG), 3. arms pulling up from lying position (EPPRKG)

(ESDRKG), 3. pulling weight with arms from lying position (ESPRKG). Evaluation of resistance in motion was based on execution of motion with $75 \%$ of maximum achieved weight, repetitive motion is carried out until the maximally correct executed repetition.

Methods for transformation, condensation and mathematical data analysis are selected according to data analysis requirements. Obtained data are subject to analysis.

Relations of variables which measured resistance in motion and the variable of anthropometric body characteristics are solved with a multiple regression analysis, the MULTREG program, from the statistic program "STAT - PACK" (Gauss - Jordan, 1954, Cooley - Lohnes, 1962). For the purpose of determining relations between predictor variables and criterion variables, the correlation coefficients between each predictor variable and criteria variable $(R)$ were calculated, as were the regressive coefficient of predictor variables (BETA), the standard error of regressive coefficients (SIGMA-D), the $T$-values of the regressive coefficient of determination of criterion variables (DELTA) and coefficients of regression T(BETA). Furthermore, the coefficients of determination of criteria variables were also calculated, as well as coefficients of multiple correlations between predictor variables and criterion variables (RO) that are derived from a routine evaluation prognosis (SIGMA-D). The analysis of variance tested the hypothesis that the population to which the sample belongs to, the coefficient of determination of criteria variables is equal to zero. For this purpose quadrant sums were calculated, degrees of freedom and middle quadrant, which belong to the linear regression and deviation from the linear regression. In addition, sums of middle quadrants were also calculated for the total variance source. The hypothesis about the nullity of coefficients of determination was tested with an $\mathrm{F}$ - test. The percentage of contribution of predictor variables explains the total variances of the criterion variable $(\mathrm{P})$ and $(\mathrm{Q})$ significance of $\mathrm{F}$ - test at a reliability level of .99 and .95 along with DF1 and DF2 degrees of freedom, if the real value of the coefficient of determination is zero (Cooley,W.W.,Lohnes,P.H., 1971).

\section{Results}

Variables of anthropometric characteristics in relation to resistance in motion, lifting with legs in repetitive motion (ESDNKG) Table 1, significantly contributes to the prediction.

Table 1. Multiple regression of variable (ESDNKG) resistance in motion, lifting legs in recurring motion in the system of anthropometric variables

\begin{tabular}{|c|c|c|c|c|c|}
\hline \multicolumn{2}{|c|}{ VARIABLES } & $\mathrm{R}$ & BETA & SIGMA-B & T(BETA) \\
\hline 1 & AVT & -0.01 & -1.49 & 0.95 & -1.56 \\
\hline 2 & AT & -0.13 & -0.35 & 1.13 & -0.31 \\
\hline 3 & ADN & -0.15 & -1.50 & 1.13 & -1.32 \\
\hline 4 & ADR & 0.11 & 3.49 & 2.15 & 1.62 \\
\hline 5 & ASK & 0.03 & -4.64 & 7.93 & -0.58 \\
\hline 6 & ADL & 0.05 & 0.88 & 5.53 & 0.15 \\
\hline 7 & ADRZ & 0.04 & -6.34 & 5.50 & -1.15 \\
\hline 8 & ADK & 0.16 & 1.77 & 1.12 & 1.57 \\
\hline 9 & AOG & 0.24 & 1.14 & 0.95 & 1.19 \\
\hline 10 & $\mathrm{AON}$ & 0.22 & 0.76 & 3.51 & 0.21 \\
\hline 11 & AONK & 0.26 & -0.19 & 2.84 & -0.06 \\
\hline 12 & $\mathrm{AOP}$ & 0.17 & -0.83 & 1.94 & -0.42 \\
\hline 13 & AKNL & 0.12 & 1.15 & 1.14 & 1.00 \\
\hline 14 & AKNT & 0.01 & -1.63 & 0.89 & -1.83 \\
\hline 15 & AKNP & -0.01 & -0.62 & 0.88 & -0.70 \\
\hline DELTA & RO & SIGMA-D & $\mathrm{F}$ & $\mathrm{P}$ & Q \\
\hline 0.25 & 0.50 & 270.99 & 2.41 & $14.76 \%$ & 0.05 \\
\hline
\end{tabular}

Key: ATV - body height, ADN - leg length, ADR - arm length, ASK bioacromial range, ADL - elbow diameter, ADRZ - wrist diameter, $\mathrm{ADK}$ - knee diameter, AT - body weight, AOG - middle range of chest, AON - upper arm range - extended, AONK - upper arm range - bent, AOP - shin range, AKNL - cutaneous back fold, AKNT - - cutaneous stomach fold, AKNP - - cutaneous shin fold.

$\mathrm{R}$ - coefficients of correlation between every predictor variable and criterion variable

BETA - regression coefficients of predictor variables

SIGMA-B - standard error of regression coefficients

T(BETA) - values of regression coefficient

DELTA - coefficients of determination of criterion variables

$\mathrm{RO}$ - coefficients of multiple correlations between predictor variables and criterion variables

SIGMA-D - standard evaluation of prognosis

$\mathrm{F}$ - test

$\mathrm{P}$ - percentage of contribution of predictor variables towards the explanation of the total variance criterion variable

$\mathrm{Q}$ - reliability

The following variables have significant cohesion in treated space: (AOG, AON, AONK, AOP) which measure body volume. And besides a small number of significant coefficients of correlation the linear combination of predictor variables forms a regressive function which ensures a satisfactory level of multiple correlation (0.50) and a coefficient of determination (0.25). Based on the obtained results in the analysis of the variance and the obtained F - test on the level of significance of 0.95 reliability, it is possible to conduct predictions of the criterion variable on the basis of a variable group of anthropometric characteristics. In this process, the fraction 
of the explained variance, to which the variable system of anthropometric characteristics contributes towards, amounts to $14.76 \%$ of the total amount of variability which can be ascribed to multiple regression. This enables acceptance of the statement that anthropometric characteristics are a significant factor in solving repetitive motions in leg lifting with a load, as well as the fact that subjects with the aforementioned characteristics in principle achieve better results in overcoming resistance in motion. Observing the obtained results within the space of variables of anthropometric characteristics in relation to the resistance in motion, lifting with arms in repetitive motion (ESDRKG), Table 2, a significant impact is noticed.

Table 2. Multiple regression of variable (ESDRKG) resistance in motion, raising arms in recurring motion within the system of anthropometric variables

\begin{tabular}{|c|c|c|c|c|c|}
\hline \multicolumn{2}{|c|}{ VARIABLES } & \multirow{2}{*}{$\frac{\mathrm{R}}{0.15}$} & \multirow{2}{*}{$\frac{\text { BETA }}{0.57}$} & \multirow{2}{*}{$\frac{\text { SIGMA-B }}{0.64}$} & \multirow{2}{*}{$\frac{\mathrm{T}(\mathrm{BETA})}{0.87}$} \\
\hline 16 & AVT & & & & \\
\hline 17 & $\mathrm{AT}$ & 0.12 & 0.00 & 0.76 & 0.00 \\
\hline 18 & $\mathrm{ADN}$ & 0.08 & -0.49 & 0.76 & -0.64 \\
\hline 19 & $\mathrm{ADR}$ & 0.06 & -1.59 & 1.45 & -1.09 \\
\hline 20 & ASK & 0.22 & 3.64 & 5.37 & 0.67 \\
\hline 21 & ADL & 0.15 & -0.22 & 3.75 & -0.06 \\
\hline 22 & ADRZ & 0.22 & -1.86 & 3.72 & -0.49 \\
\hline 23 & $\mathrm{ADK}$ & 0.32 & -0.49 & 0.76 & -0.65 \\
\hline 24 & AOG & 0.38 & 1.30 & 0.65 & 2.01 \\
\hline 25 & $\mathrm{AON}$ & 0.40 & 2.74 & 2.37 & 1.15 \\
\hline 26 & AONK & 0.39 & 0.73 & 1.92 & 0.38 \\
\hline 27 & AOP & 0.30 & -0.23 & 1.31 & -0.17 \\
\hline 28 & AKNL & 0.10 & -0.56 & 0.77 & -0.73 \\
\hline 29 & AKNT & 0.11 & -0.20 & 0.60 & -0.33 \\
\hline 30 & AKNP & 0.10 & -0.10 & 0.60 & -0.18 \\
\hline DELTA & RO & SIGMA-D & $\mathrm{F}$ & $\mathrm{P}$ & Q \\
\hline 0.24 & 0.49 & 183.59 & 2.26 & $13.39 \%$ & 0.05 \\
\hline
\end{tabular}

Significant correlations in analyzed space are conditioned by variables (AOP, AONK, AON, AOG) that measured body volume and variables (ADK, ADRZ, ASK) that measured the skeletal transversal dimensionality.

The linear combination of variables produced a significant coefficient of multiple correlation (0.49) and a coefficient of determination (0.24). Obtained values ensure adequate data in order to accept the statement that the joint reproduces common variances to such a degree based on which a prediction of the stated motion can be carried out - resistance in motion by lifting arms (ESDRKG), with anthropometric characteristics.

This was also confirmed in the variance analysis where the F - test holds a statistical significance of 0.95 reliability level. It can be confirmed that anthropometric characteristics significantly contribute to the prediction of the stated motion. This is supported by the fraction of the explained variance which covers $13.39 \%$ of the total variability, and which can be ascribed to multiple regression.

The system of anthropometric characteristics variables in relation to resistance in motion, pulling with arms in repetitive motion (ESPRKG), Table 3, ensures a sufficient level of influence.
Table 3. Multiple regression of variable (ESPRKG) resistance in motion, pulling with arms in recurring motion within the system of anthropometric variables

\begin{tabular}{|c|c|c|c|c|c|}
\hline \multicolumn{2}{|c|}{ VARIABLES } & \multirow{2}{*}{$\frac{\mathrm{R}}{0.31}$} & \multirow{2}{*}{$\begin{array}{c}\text { BETA } \\
-0.49\end{array}$} & \multirow{2}{*}{$\frac{\text { SIGMA-B }}{0.64}$} & \multirow{2}{*}{$\frac{\mathrm{T}(\mathrm{BETA})}{-0.76}$} \\
\hline 31 & AVT & & & & \\
\hline 32 & AT & 0.30 & 0.89 & 0.75 & 1.17 \\
\hline 33 & $\mathrm{ADN}$ & 0.28 & 0.61 & 0.76 & 0.81 \\
\hline 34 & ADR & 0.14 & -2.29 & 1.44 & -1.59 \\
\hline 35 & ASK & 0.40 & 5.70 & 5.32 & 1.07 \\
\hline 36 & $\mathrm{ADL}$ & 0.26 & -1.27 & 3.71 & -0.34 \\
\hline 37 & ADRZ & 0.40 & -0.36 & 3.69 & -0.10 \\
\hline 38 & $\mathrm{ADK}$ & 0.48 & 0.41 & 0.75 & 0.54 \\
\hline 39 & AOG & 0.45 & 0.32 & 0.64 & 0.51 \\
\hline 40 & $\mathrm{AON}$ & 0.50 & 5.28 & 2.35 & 2.24 \\
\hline 41 & AONK & 0.50 & -1.15 & 1.90 & -0.60 \\
\hline 42 & $\mathrm{AOP}$ & 0.46 & 0.81 & 1.30 & 0.62 \\
\hline 43 & AKNL & 0.12 & 0.26 & 0.76 & 0.34 \\
\hline 44 & AKNT & 0.07 & -0.99 & 0.59 & -1.65 \\
\hline 45 & AKNP & 0.08 & -0.59 & 0.59 & -0.99 \\
\hline DELTA & RO & SIGMA-D & $\mathrm{F}$ & $\mathrm{P}$ & $\mathrm{Q}$ \\
\hline 0.42 & 0.65 & 181.86 & 5.22 & $34.01 \%$ & 0.01 \\
\hline
\end{tabular}

The largest and most positive connection in the space of predictors have the following variables (AOP, AONK, AON, AOG, AT) which measure body volume, variables (ADK, ADRZ, ADL, ASK) which measure transversal skeletal dimensionality and variables (AVT, ADN) which measure the longitudinal skeletal dimensionality.

The linear combination of variables produced a multiple correlation which is satisfactory and significant (0.65). It is clear that in the process of forming the regression function, the stated variables contributed the most. The obtained results especially the satisfactory coefficient of determination - 0.42, determined on teh basis of the anthropometric characteristics system, validate the evaluation that resistance in motion, pulling with arms in repetitive motion is dependent on anthropometric characteristics.

The analysis of variance and the obtained F - test which is statistically significant on a level of 0.99 reliability, ensures a significant evaluation of the fraction which can be ascribed to multiple regression. A part of the variance that can be explained by the system of predictor variables amounts to $34.01 \%$ of the total variability, ensuring the statement that resistance in motion, pulling with arms in repetitive motion is dependent on anthropometric characteristics.

\section{Discussion}

The research was carried out on a sample of 124 subjects, 15-16 year old males. An analysis was performed of the relations of anthropometric body characteristics and overcome resistance in recurring motion. The evaluation of resistance in motion was based on conducting motion with $75 \%$ of the maximum achieved, overcome weight, repetitive motion is carried out until the maximum number of correctly executed repetitions. Obtained information was submitted for mathematical analysis, the MULTREG program, from the statistical program "STAT - PACK" 
(Gauss - Jordan, 1954, Cooley - Lohnes, 1962). On the basis of maximum cohesion and regressive coefficients, calculated $\mathrm{T}$-values of regressive coefficients between predictor variables and criterion variables, confirmed the significance of the prediction. The Nullity Hypothesis of coefficient determination was tested with the $\mathrm{F}$ - test. The percentage of contribution predictor variables explain the total variances of the criterion variable $(\mathrm{P})$ and $(\mathrm{Q})$ the significance of the $\mathrm{F}$ - test on a level of reliability of .99 and .95 along with DF1 and DF2 degrees of freedom, confirmed the stated significance. Variables that measured body volume, transversal skeletal dimension and longitudinal skeletal dimension proved to have the highest cohesion with the overcome maximum resistance in recurring motion from anthropometric body characteristics. High cohesion of variables of the overcome maximum resistance in recurring motion with anthropometric body characteristics indicates that a part of the resistance variable in motion is conditioned by mutable flexible anthropometric values. As the overcome maximum resistance in motion is mainly conditioned by the structure for generating intensity and duration of energy release, thus the anthropometric dimensions, especially in the volume segment, body volume and transversal skeletal dimensionality, present a factor that significantly participates in the realization of motion with increased requirements for overcoming maximum resistance in motion.

\section{References}

[1] Blašković, M. Relacije morfoloških karakteristika i motoričkih sposobnosti. Kineziologija 1-2. Zagreb. [Relations of Morphological Characteristics and Motor Abilities, Kinesiology 12]. 1979.

[2] Clarke, D.H., Glines, D. Relationships of reaction, Cnvoment, and competion times to motor, stringth, antropometric and maturity measures of 13-Year - old Boys. Research Quarterly, No. 2. 1962.
[3] Cooley,W.W.,Lohnes, P. H. Multivariate data analisis. John Wiley.New York. 1971.

[4] Dodig, M. Biomehanika čovječjeg tijela [Biomechanics of the Human Body] Rijeka: University of Rijeka. 1994.

[5] Dodig, M. Modeli i modeliranje tjelovježbenih procesa [Model and Modelling Physical Training Process]. Rijeka: University of Rijeka. 2002.

[6] Dodig, M. Mehanizmi regulacije gibanja čovječjeg tijela - osnove kineziologije [Mechanisms Regulate Motion Human of Body Basis Kinesiology] Rijeka: University of Rijeka. 2008.

[7] Dodig, M. Factorial Structure of Basic Kinetic Elements // Proceedings of the 5th International Congress Youth Sport 2010. The Heart of Europe.Ljubljana / Ljubljana : Faculty of Sport, 203218. 2010.

[8] Dodig, M. Canonical relations between basic kinetic elements and morphological characteristics // Proceedings of the 5th International Congress Youth Sport: The Heart of Europe / Ljubljana : Faculty of Sport. 191-201. 2010.

[9] Dodig, M. Relacije između otpora i brzine unutar jednostavnog gibanja // Zbornik radova III. kongresa pedagoga fizičke kulture Jugoslavije / Novi Sad : Savez pedagoga fizičke kulture Vojvodine. 71-76 [Relations Between Resistance and Velocity Within Simple Motion // Collection of Papers $3^{\text {rd }}$ Congress of Physical Education Pedagogues in Yugoslavia/ Novi Sad: Union of Physical Education Pedagogues]. 1987.

[10] Dodig, M. Canonical Relations Between Basic Kinetic Elements and Motor Abilities // 4th International Symposium Youth Sport 2008 The heart of Europe : book of Abstracts / Ljubljana : Faculty of Sport. 86-86. 2008.

[11] Momirović, K., Gredelj, M., Herak, M. COCAIN - algoritam i program za kanoničku korelacijsku analizu [COCAIN - algoritam and program for canonical correlative analysis]. Kineziologija, (1 - 2).1980.

[12] Strel, J., Šturm, J., Pistotnik, B. Zanesljivost in struktura nekaterih motoričnih sposobnosti in morfoloških značilnosti šest in pol letnih učencev in učenk [Reliability and structure of some motor abilities and morphological characteristics of 6.5-year-old boys and girls]. Ljubljana: Visoka šola za telesno kulturo. 1981.

[13] Tappen, N.C. An antropometric and constitutional study of championship . weight lifter. Amer. J. Physic. Anthrop. No. 1. 1950.

[14] Zakrajšek, E., Hošek, A., Stojanović, M., Lanc, M., Momirović, K. Utjecaj antropometrijskih dimenzija na silu mjerenu dinamometrom. Kineziologija, 1-2. [Impact of Anthropometric Dimensions on Force Measured with a Dinamometer]. 1976. 